\title{
Generation of Human-Induced Pluripotent Stem Cells from Peripheral Blood Mononuclear Cells using Small-Molecule Compound VC6TFZ
}

\author{
Aprihati Aprihati*, B. S. Pikir, Andrianto Andrianto \\ Department of Cardiology and Vascular Medicine, Airlangga University, Surabaya, Indonesia
}

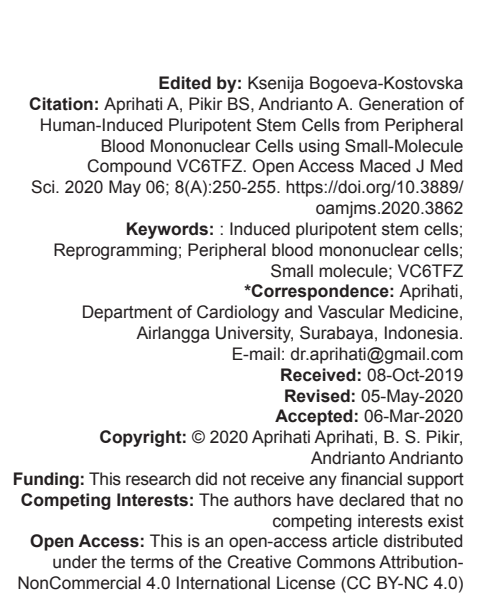

Introduction

Pluripotent stem cells play an important role in regenerative medicine due to their ability to differentiate into all cell types and unlimited self-renewal. The common source of pluripotent stem cells was embryonic stem cells (ESCs) which are generated from inner cell mass of embryo at blastocyst stage. The use of ESCs was controversial due to some ethical issue related to embryo destruction, risk of immune rejection, and limited source due to embryo origin. Induced pluripotent stem cells (iPSCs) have been an alternative source of pluripotent stem cells which tackled the ethical issue because it originates from somatic cells. Potential application of iPSCs such as provides cells for cell transplantation therapy, disease modeling, and drug screening [1].

iPSCs were generated from somatic cells by reprogramming process using various reprogramming factors. Skin fibroblast cells were the first source cells and still being the most frequently used [2], [3]. Skin biopsy procedures were uncomfortable, leave scar tissue, and require a long time for fibroblast cell expansion, limiting the use of fibroblasts as a source of iPSCs. Other source cells were keratinocytes, mesenchymal stem cells from adipose tissue, cord blood cells, and peripheral blood cells. Peripheral blood cells were one of the attractive sources of iPSCs because easy to collect, minimally invasive, and can be stored in a frozen form [4].

Blood cells were continuously replaced by stem cells in bone marrow, made these cells less susceptible to environment-associated point mutation than skin which exposed to ultraviolet light. The quality of iPSCs derived from peripheral blood mononuclear cell (PBMNC) and fibroblasts was equivalent and difficult to distinguish from ESCs. iPSCs derived from PBMNC were comparable to ESCs in terms of morphology, expression of surface antigens, activation of endogenous pluripotent genes, DNA methylation, and differentiation abilities [5].

Since its discovery, iPSCs were generated through transduction of exogenous transcription factors OCT4, SOX2, KIf4, and c-Myc (OSKM) into the nucleus of somatic cells transferred using retroviruses [2], [3]. The reprogramming process which used exogenous transcription factors with integrative systems associated with low efficiency, risk of mutagenesis, and tumorogenesis thereby limiting their use for clinical 
applications. Various approaches were made to improve the efficiency and safety of iPSCs for clinical applications, one of the strategies was the use of small molecules [6].

At present, small molecules have an important role in reprogramming. Small molecules that worked on signaling pathways, epigenetic modifications, and metabolic processes had been widely used to improve reprogramming efficiency using exogenous transcription factors. The combination of several small molecules could induce pluripotency despite without exogenous transcription factors [7]. Small molecules were cell permeable and non-immunogenic. Small molecules were more cost efficient, easy to manufacture, can be stored, and standardized. Another advantage was that it did not involve genetic manipulation so it was safer, had fast biological effect, reversible, the effect can be controlled by modifying dosage and combinations [8].

VC6TFZ was a combination of small molecules consisting of valproic acid (VPA), CHIR990210 (CHIR), 616452 (Repsox), tranylcypromine, forskolin, 3-deazaneplanocin (DZnep), and 4-[(E)-2-(5,6,7,8Tetrahydro-5,5,8,8-tetramethyl-2-naphthalenyl)-1propenyl]benzoic acid, or also called TTNPB. The combination of these small molecules could induce pluripotency in mouse embryonal fibroblasts (MEFs) with higher efficiency than the Yamanaka protocol that used exogenous transcription factors $(0.02 \%$ vs. $0.001-$ $0.01 \%$ ) [9]. This study was the first study aimed to prove whether the small-molecule compound VC6TFZ could induce pluripotency in human PBMNC.

\section{Methods}

This study was a post-test control group only design in vitro study. This study protocol, as shown in Figure 1, consisted of several steps including PBMNC isolation, PBMNC culture, pluripotency induction using small molecules, and iPSCs identification. Blood samples were derived from a 31-year-old female volunteer.

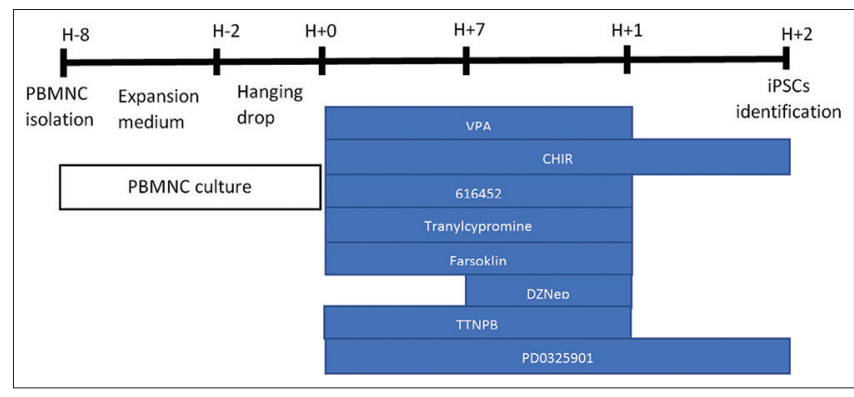

Figure 1: Study protocol

\section{PBMNCs isolation}

Blood was collected into heparin-coated tubes. Collected blood was diluted with 5 cc phosphate-buffered saline (PBS) and centrifuged through a Ficoll gradient for $30 \mathrm{~min}$ at $1600 \times \mathrm{g}$. PBMNCs were collected and transferred to a new tube and add $10 \mathrm{cc}$ PBS, centrifuged for $5 \mathrm{~min}$ at $2000 \times \mathrm{g}$. Supernatant was aspirated and resuspend at $10 \mathrm{cc}$ PBS.

\section{Peripheral blood mononuclear culture}

PBMNCs were cultured at Roswell Park Memorial Institute (RPMI) medium enriched with L-glutamine $1 \mathrm{~mL} / 100 \mathrm{~mL}$, ITS $1 \mathrm{~mL} / 100 \mathrm{~mL}$, FGF $5 \mathrm{ng} / \mathrm{uL}$, ascorbic acid $5 \mathrm{mg} / 100 \mathrm{~mL}$, GMCSF $50 \mathrm{uL} / 100 \mathrm{~mL}$, and dexamethasone $100 \mathrm{uL} / 100 \mathrm{~mL}$. Mononuclear cells were cultured for 6 days, and medium was changed every 3 days. After 6 days culture at RPMI medium, PBMNCs were cultured using hanging drop method for 2 days. Hanging drop cultured was done by dripping the cell suspension using tip of the pipette at $5 \mathrm{~cm}$ Petri dish cover. The cover dish then reversed, continued with incubating cells at $37^{\circ} \mathrm{C} \mathrm{CO}_{2}$ for 48 hours without adding medium.

\section{Pluripotency induction using small- molecule compound VC6TFZ}

Three drops of mononuclear cell suspension were transferred to $\mathrm{M}-24$ well plate pre-coated with vitronectin overnight and feeder cells. Feeder cells were made from mitosis-inactivated rabbit adipose mesenchymal cells using mitomycin-C $2 \mu \mathrm{g} / \mathrm{mL}$ for $30 \mathrm{~min}$. Add ReproTesR medium which contained smallmolecule VC6TF. At day 7, DZnep was added. Cells were exposed to small molecules for 14 days. The medium was changed every 4 days. On day 14, VC6TFZ was changed to $2 \mathrm{i}$ medium (PD0325901 and CHIR) for 7 days.

The cells were grouped into four groups. Group 1 (P1) was the control group, which was not exposed to small molecule. Group 2 (P2) was the experimental groups which exposed to small-molecule dosage VPA $0.5 \mathrm{mM}$, CHIR 5 uM, $6164525 \mathrm{uM}$, tranylcypromine 2.5 uM, FSK 20 uM, DZnep $20 \mathrm{nM}$, and TTNPB 5 uM. Group 3 (P3) was the experimental groups which exposed to small-molecule dosage VPA 0.75 mM, CHIR 10 uM, 6164527.5 uM, tranylcypromine 5 uM, FSK 40 uM, DZnep 50 nM, and TTNPB 5 uM. Group 4 (P4) was the experimental groups which exposed to small-molecule VPA $1 \mathrm{mM}$, CHIR $20 \mathrm{uM}$, $61645210 \mathrm{uM}$, tranylcypromine $10 \mathrm{uM}$, FSK $60 \mathrm{uM}$, DZnep 100 nM, and TTNPB 5 uM.

\section{iPSCs identification}

Identification of iPSCs was done by morphology identification and expression of pluripotency markers (SOX2 and OCT4). iPSC colonies had large characteristics, tight and clear border, and cobble stone-like appearance. In iPSC colonies, cells had a small size with a large ratio of cytoplasmic nuclei. 


\section{Immunohistochemical staining}

Cells were fixed with methanol for $10 \mathrm{~min}$, then wash with cold PBS 2 times. The cells were then stabilized with $0.25 \%$ Triton $\mathrm{X}-100$ on PBS for 10 min at room temperature. The cells were washed with PBS 3 times for $5 \mathrm{~min}$. Cells were incubated with $1 \%$ bovine serum albumin (BSA) in phosphate-buffered saline with Tween (PBST) for $30 \mathrm{~min}$. Cells were then incubated in antibody solution (OCT4 and SOX2) in 1\% BSA in PBST in humidified chamber for $1 \mathrm{~h}$ at room temperature or overnight at $4^{\circ} \mathrm{C}$. The procedure continued with washing the cells for 5 minutes with PBS, repeated for 3 times. The cell was then incubated with the Alexa Fluor 488 goat anti-mouse IgG secondary antibody. Fluorescent signal is then viewed under a microscope.

\section{Statistical analysis}

Collected data were coded, tabulated, and statistically analyzed using the SPSS version 24 . OCT4 and SOX2 expressions will be presented mean \pm SD. Data normality test was done using KolmogorovSmirnov test. Differences in OCT4 expression and SOX2 expression between the four groups will be analyzed by one-way ANOVA test if the data were normally distributed and Kruskal-Wallis if the data were not normally distributed. The difference was said to be significant if $p<0.05$.

\section{Results}

iPSCs like colony were appeared at day 9 after cells were exposed to small molecule. Colonies had large and round morphology with cobble stone-like appearance (Figure 2).

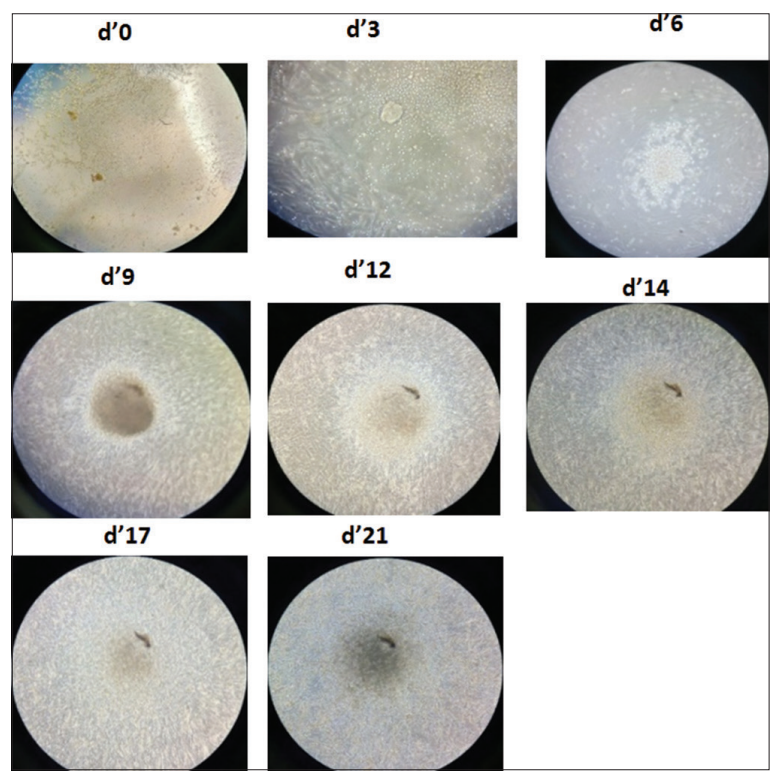

Figure 2: Changed of colonies morphology at day 0-day 21
All colonies were expressed pluripotency markers. OCT4 expression was found in all treatment groups with the strongest expression in P3 group. Cells that had strong expressions of OCT4 will glow bright green (Figure 3), the degree of luminance will

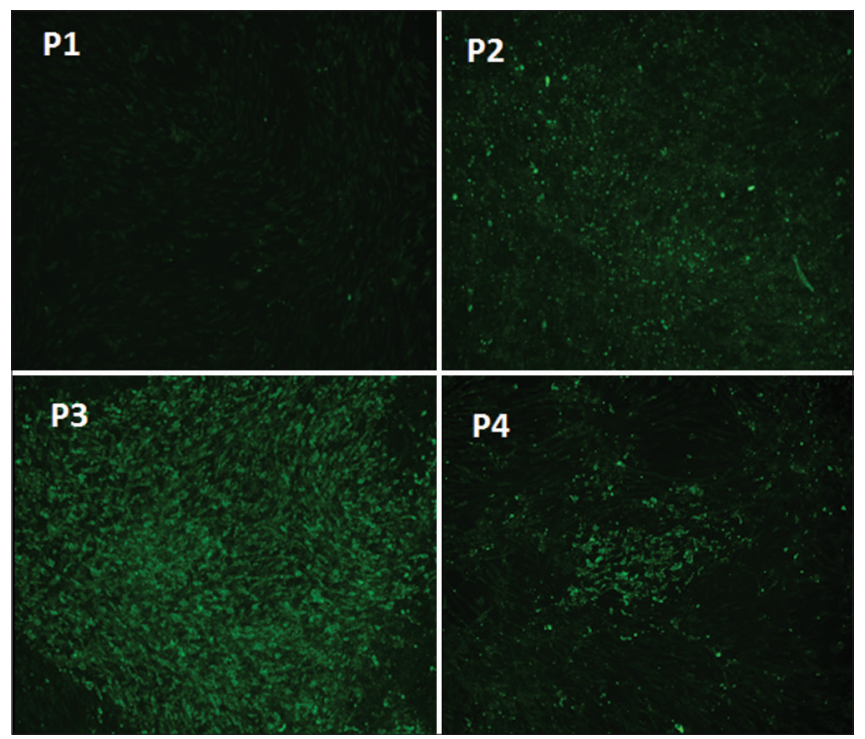

Figure 3: OCT4 expression in each group

be measured quantitatively using ImageJ software. Significant differences were found between the P3 and P4 groups with the control group ( $p=0.000, p=0.022)$, whereas between the P2 group and the control, there was no significant difference $(p=0.116)$ as shown in Table 1 .

Table 1: Comparison of OCT4 expression between groups

\begin{tabular}{lll}
\hline Control group & VC6TFZ experimental group mean \pm SD OCT4 & $\mathrm{p}$ \\
\hline $30.082 \pm 5.93$ & P2: $49.905 \pm 13.49$ & 0.121 \\
& P3: $182.185 \pm 52.70$ & 0.000 \\
& P4: $86.898 \pm 67.04$ & 0.022 \\
\hline
\end{tabular}

All colonies also expressed SOX2 markers (Figure 4)
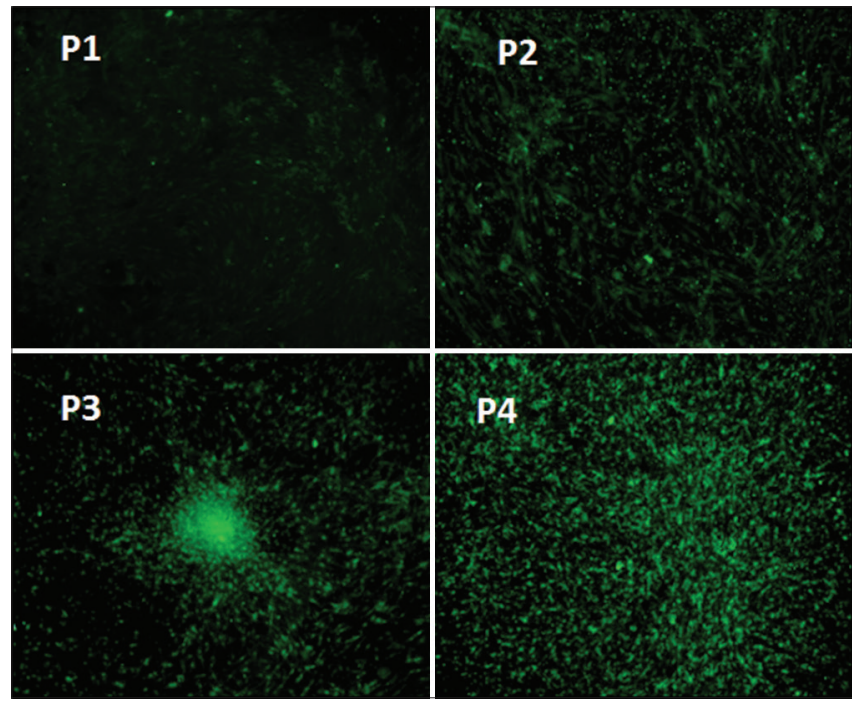

Figure 4: SOX2 expression in each group

The mean SOX2 expression was stronger in all treatment groups compared to the control group with the strongest expression found in the P3 group. There was a significant difference between the control group 
with P3 and P4 ( $p=0.028, p=0.006)$, but there was no significant difference between the control group with P2 $(p=0.116)$ as shown in Table 2.

Table 2: Comparison of SOX2 expression between groups

\begin{tabular}{lll}
\hline Control group & VC6TFZ experimental groups mean \pm SD SOX2 & p \\
\hline $44.206 \pm 35.751$ & P2: $142.441 \pm 129.542$ & 0.116 \\
& P3: $227.992 \pm 123.736$ & 0.028 \\
& P4: $171.784 \pm 61.56439$ & 0.006 \\
\hline
\end{tabular}

\section{Discussion}

iPSC s was generated from somatic cells through the reprogramming process. These stem cells had the ability to differentiate into all cell types and unlimited self-renewal abilities. This property made these cells had potential as cell sources for cell transplantation therapy, disease modeling, and drug screening [10]. The first and most widely used cell source for the generation of iPSCs was skin fibroblast cells [4], [8]. This study used PBMNNC as a source for iPSCs due to their ease of accessibility, minimally invasive, and less susceptible to point mutation [5]. Many research had been done to generate iPSCs from PBMNC, where these iPSCs had similar quality as iPSCs derived from fibroblasts [11], [12], [13]. The previous studies used Sendai virus, Lentivirus, and episomal vector for pluripotency induction in PBMNC [11], [12], [13], [14]. This study was the first study that used small molecules to induce human PBMNC pluripotency.

In this study, we found that small-molecule compound VC6TFZ could induce pluripotency in human PBMNC. It was proven by the formation of colonies that resembled iPSCs morphology and the expression of pluripotency markers (OCT4 and SOX2). In this study, we found a colony that began to appear on the $3^{\text {rd }}$ day of induction and increasingly enlarge on day 9 . The colonies had round morphology, cobble stone like, and clear edges. This colonies morphology resembles iPSCs as described in the guidelines and techniques for the generation of iPSCs [15].

The colonies in this study express pluripotency markers, OCT4 and SOX2. The expressions of each marker were analyzed quantitatively using Image $J$ software, which obtained higher expressions in all treatment groups compared to the control group. Statistically, there were significant differences between the control group and the P3 and P4 groups in OCT4 expression $(p=0,000 ; p=0.022)$ and SOX2 $(p=0.028$; $p=0.006$ ). This indicates the most optimal expression of OCT4 and SOX2 at small-molecule P3 and P4. This indicates that the effect of small molecule on the success of reprogramming was dose dependent [9], [16]. The key for reprogramming successful with small molecules was the concentration and combination of small molecules. Small molecules could be cytotoxic at certain concentrations so that at higher doses, the reprogramming efficiency was sometimes even lower [16].

The protocol we used in this study was different from the previous studies, where the induction was done in only 21 days, faster than the Hou et al. In Hou's study, GFP-positive colonies began to appear around day 10-12, while in this study, the colonies appeared earlier at day 6 . This was likely due to the optimized culture method and the hanging drop culture method. Optimization of PBMNC culture plays an important role in the reprogramming process. In this study, we cultured PBMNC for 6 days in an expansion medium. During culture period, the longer duration the more number of dead cells, but the number of living cells remains constant, so the optimal duration of culture time was needed. This 6 -day duration was based on research conducted by $\mathrm{Gu}$ et al. where this study showed that the 6-day culture time shows the number of colonies that most expressed TRA $1-60$ and AP compared to days 4.8 or 10 [17].

Hanging drop culture method allows the formation of colonies through cell aggregation induced by gravity [18]. The accumulation of cells in the drop allows the formation of spheroidal colonies. Spheroid colonies that were formed can produce extracellular matrices and environments that resemble living tissue. Inside the drop cells adhere to each other by holding on the resulting matrix. Intercell interactions and interactions between cells and extracellular matrix were better with this method [19], [20]. This method also allows more efficient diffusion of growth factors and metabolic waste disposal [21].

In this research, small-molecule compound VC6TFZ was combination of VPA, CHIR, 616452, tranylcypromin, FSK, and DZnep. The VC6TFZ combination was first discovered by Hou et al. after screening 10,000 small molecules. Hou has succeeded in generating iPSCs derived from MEF using VC6TFZ without any exogenous transcription factors [9].

The CHIR, FSK, and 616452 (Repsox) components induce the expression of Sall4 and SOX2 pluripotent genes in the early phase of the cellular reprogramming process. Concomitant overexpression between Sall4 and SOX2 can activate OCT4 promoterdriven luciferase reporter so that it is sufficient to replace C6F for OCT4 induction. Expression of OCT4 increased significantly with the addition of DZnep. DZnep was important to stimulate OCT4 expression, but not other pluripotent genes. As a S-adenosylhomocysteine hydrolase (SAH) hydrolase inhibitor, DZnep increased the concentration ratio of $\mathrm{SAH}$ and S-adenosylmethionine (SAM), thereby reducing the SAM-dependent cellular methylation process. The role of DZNep in OCT4 activation occurs through decreased DNA and $\mathrm{H} 3 \mathrm{~K} 9$ methylation in the OCT4 promoter region. OCT4 and SOX2 then activate other pluripotent genes such as Nanog. SOX2, OCT4, and Nanog activated each other to form a pluripotency circuit that maintains the pluripotent nature of a cell. 
OCT4 expression expressed in somatic cells through various epigenetic modifications, opened with a chemical cellular reprogramming process using the DZnep epigenetic modulator, and stimulated by C6Finduced expression Sox2-Sall4 [9].

One of the challenges in reprogramming PBMNC was that these cells had non-adherent nature [13]. To overcome this problem, we coated the well walls using vitronectin and feeder cells that enable the PBMNC attachment on the well. This attachment was important to avoid cell lost during medium replacement. Previously, we only used vitronectin to coat the well, but the cells were still not adherent so we decided to make feeder cells. This feeder cell produces stemness-supporting factors that prevent spontaneous differentiation. This feeder cell produced adhesion molecules and extracellular matrix that increases attachment of iPSCs which supports growth and survival [22], [23].

Other feeder cells types used for in ESC/iPSCs production such as MEFs, STO cells, and SNL 76/7 cells. The most widely used was MEF proliferation-inactivated using mitomycin-C or gamma $\mathrm{X}$-ray. Inactivation of mitosis or MEF irradiation stimulated the expression of several proteins such as Wnt-3 that contributed to molecular mechanisms in maintaining pluripotency. MEFs produced various proteins such as transforming growth factor beta 1 , activin $A$, bone morphogenetic protein-4, and pleitrophin (heparin-binding growth factor). Vitronectin was an extracellular matrix protein that was rich in peptide arginine-glycine-aspartate (RGD) needed for integrin-mediated cell adhesion and growth through cellular pathway activation. Vitronectin also supports self-renewal and pluripotency from ESC [22]. In this study, we used rabbit adipose mesenchymal cells which mitosis-inactivated using $2 \mu \mathrm{g} / \mathrm{mL}$ mitomycin-C for $30 \mathrm{~min}$. This dose was smaller than the dose used in the literature for MEFs which was $10 \mu \mathrm{g} / \mathrm{mL}$ [23], [24].

\section{Conclusion}

This was the first study that showed smallmolecule compound VC6TFZ could induce pluripotency in human PBMNC. Further research was needed to analyze molecular profile, differentiation, and selfrenewal ability of these cells. For clinical application, the safety profile related to the risk of tumorogenesis and genetic instability also needed further investigation.

\section{Acknowledgments}

The authors would like to thank to Rizka Amalia, MD for her contribution in this research.

\section{References}

1. Singh VK, Kalsan M, Kumar N, Saini A, Chandra R. Induced pluripotent stem cells: Applications in regenerative medicine, disease modeling, and drug discovery. Front Cell Dev Biol. 2015;3:1-18. https://doi.org/10.3389/fcell.2015.00002 PMid:25699255

2. Takahashi K, Yamanaka S. Induction of pluripotent stem cells from mouse embryonic and adult fibroblast cultures by defined factors. Cell. 2006;126(4):663-76. https://doi.org/10.1016/j. cell.2006.07.024

PMid:16904174

3. Takahashi K, Tanabe K, Ohnuki M, Narita M, Ichisaka T, Tomoda K, et al. Induction of pluripotent stem cells from adult human fibroblasts by defined factors. Cell. 2007;131(5):861-72. https://doi.org/10.1016/j.cell.2007.11.019

PMid: 18035408

4. Raab S, Klingenstein M, Liebau S, Linta L. A comparative view on human somatic cell sources for iPSC generation. Stem Cells Int. 2014;2014:768391. https://doi.org/10.1155/2014/768391

5. Loh YH, Hartung O, Li H, Guo C, Sahalie JM, Manos PD, et al Reprogramming of $\mathrm{T}$ cells from human peripheral blood. Cell Stem Cell. 2010;7(1):15-9.

PMid:20621044

6. Attwood S, Edel M. iPS-cell technology and the problem of genetic instability can it ever be safe for clinical use? J Clin Med. 2019;8(3):288. https://doi.org/10.3390/jcm8030288

PMid:30823421

7. Baranek M, Belter A, Naskre MZ, Stobiecki M, Markiewicz WT, Barciszewski J. Effect of small molecules on cell reprogramming. Mol Biosyst. 2017;13(2):277-313. https://doi.org/10.1039/ c6mb00595k

PMid:27918060

8. Qin H, Zhao A, Fu X. Small molecules for reprogramming and transdifferentiation. Cell Mol Life Sci. 2017;74(19):3553-75. https://doi.org/10.1007/s00018-017-2586-x PMid:28698932

9. Hou P, Li Y, Zhang X, Liu C, Guan J, Li H, et al. Pluripotent stem cells induced from mouse somatic cells by small-molecule compounds. Science. 2013;341(6146):651-4. https://doi. org/10.1126/science.1239278 PMid:23868920

10. Gomes KM, Costa IC, Santos JF, Dourado PM, Forni MF, Ferreira JC. Induced pluripotent stem cells reprogramming: Epigenetics and applications in the regenerative medicine. Rev Assoc Med Bras. 2017;63(2):180-9. https://doi. org/10.1590/1806-9282.63.02.180

PMid:28355380

11. Kim Y, Rim YA, Yi H, Park N, Park SH, Ju JH. The generation of human induced pluripotent stem cells from blood cells: An efficient protocol using serial plating of reprogrammed cells by centrifugation. Stem Cells Int. 2016;2016:1329459. https://doi. org/10.1155/2016/1329459

PMid:27579041

12. Wen W, Zhang JP, Chen W, Arakaki C, Li X, Baylink D, et al. Generation of integration-free induced pluripotent stem cells from human peripheral blood mononuclear cells using episomal vectors. J Vis Exp. 2017;2017(119):1-7. https://doi. org/10.3791/55091

PMid:28117800

13. Ye $H$, Wang $Q$. Efficient generation of non-integration and feeder-free induced pluripotent stem cells from human peripheral blood cells by sendai virus. Cell Physiol Biochem. 
2018;50(4):1318-31. https://doi.org/10.1159/000494589 PMid:30355953

14. Su RJ, Neises A, Zhang X. Generation of iPS cells from human peripheral blood mononuclear cells using episomal vectors. Methods Mol Biol. 2016;1357:57-69. https://doi. org/10.1007/7651_2014_139

PMid:25403468

15. Maherali N, Hochedlinger K. Guidelines and techniques for the generation of induced pluripotent stem cells. Cell Stem Cell. 2008;3(6):595-605. https://doi.org/10.1016/j.stem.2008.11.008 PMid:19041776

16. Zhou J, Sun J. A revolution in reprogramming: Small molecules. Curr Mol Med. 2019;19(2):77-90.

PMid:30914022

17. Gu H, Huang X, Xu J, Song L, Liu S, Zhang XB, et al. Optimizing the method for generation of integration-free induced pluripotent stem cells from human peripheral blood. Stem Cell Res Ther. 2018;9(1):1-10. https://doi.org/10.1186/s13287-018-0908-z PMid:29907164

18. Rungarunlert S. Embryoid body formation from embryonic and induced pluripotent stem cells: Benefits of bioreactors. World J Stem Cells. 2009;1(1):11-21. https://doi.org/10.4252/wjsc. v1.i1.11

\section{PMid:21607103}

19. Foty R. A simple hanging drop cell culture protocol for generation of 3D spheroids. J Vis Exp. 2011;(51):2-6. https:// doi.org/10.3791/2720

PMid:21587162

20. Antarianto RD, Septiana WL, Jusuf AA, Barasila AC, Pawitan JA, Fasha I. Perbandingan ko-kultur 2D dan 3D dengan metode hanging drop untuk menghasilkan micro-environment yang lebih relevan secara klinis. eJ Kedokt Indones. 2017;5(2):121-6. https://doi.org/10.23886/ejki.5.7701

21. Jitcy SJ, Malindisa ST, Ntwasa M. $2 D$ and $3 D$ Cell Culture in Drug Discovery. London: Intech; 2016.

22. Yu G, Kamano $Y$, Wang F, Okawa H, Hirofumi $Y$, Egusa $H$. Feeder cell sources and feeder-free methods for human iPS cell culture. In: Interface Oral Health Science. Berlin: Springer; 2015. p. 351. https://doi.org/10.1007/978-4-431-55192-8_12

23. Li P, Wang S, Zhan L, HeX, Chi G, LvS, et al. Efficient feeder cells preparation system for large-scale preparation and application of induced pluripotent stem cells. Sci Rep. 2017;7(1):1-15. https://doi.org/10.1038/s41598-017-10428-5 PMid:28947775

24. Conner DA. Mouse embryo fibroblast (MEF) feeder. Curr Protoc Mol Biol. 2000;23(2):1-23.

PMid:18265203 